Diabetologia 11, 15-20 (1975)

(C) by Springer-Verlag 1975

\title{
ORIGINALS
}

\section{The Relationship between Diagnostic Information Obtained from Three Tests for Detecting Mild Diabetes Mellitus}

\author{
K. Johansen \\ Second University Clinic of Internal Medicine, Kommunehospitalet, Aarhus, Denmark \\ Received: March 25, 1974, and in revised form: August 23, 1974
}

\begin{abstract}
Summary. The purpose of the study was to evaluate and compare the most commonly used criteria for the interpretation of the oral (OGTT) and intravenous (IVGTT) glucose tolerance tests and the intravenous tolbutamide test (IVTT) and to establish the criteria that give the highest degree of diagnostic agreement. The highest degree of diagnostic agreement was obtained with the following limits: a) blood glucose $>$ or $\leq 120 \mathrm{mg} / 100 \mathrm{ml}$ within $21 / \mathrm{h}$ after a $100 \mathrm{~g}$ OGTT together with $b$ ) a $k$-value of $>$ or $\leq 1.05$ as a limit for a $25 \mathrm{~g}$ IVGTT and c) a $30 \mathrm{~min}$ blood glucose level as percentage of fasting of $>$ or $\leq 77$ as limit for a $1 \mathrm{~g}$ IVTT. Using these criteria the three tests deemed the same subjects either diabetic or nondiabetic in about $2 / 3$ of the cases. The best correlation between the blood glucose values of the OGTT and the k-values of the IVGTT and the $30 \mathrm{~min}$ values
\end{abstract}

of the IVTT was obtained using the blood glucose concentrations of the last part of the OGTT. The 2 and the $3 \mathrm{hr}$ values were however equal to the $2 \frac{1}{2} \mathrm{hr}$ values with regard to the degree of correlation with the values of the intravenous test. The results indicated that the diagnostic disagreement reported previously between the three tests may partly be due to the use of blood glurose values in the first part of the OGTT for the classification of the test and partly due to the screening limits chosen for interpretation of the three test.

Key words: Diabetes mellitus, oral glucose tolerance test, intravenous glucose tolerance test, intravenous tolbutamide test, diagnostic criteria, concordance between tolerance tests.
The increasing interest in discovering diabetes mellitus in its mildest and even asymptomatic forms has two main reasons. The first is that the study of the biochemical and endocrinological disturbances in this stage of the disease might give a clue to the etiology and pathogenesis of diabetes mellitus. The second is that even subjects with subclinical diabetes may require treatment, for they may also develop diabetic angiopathy [1].

The glucose intolerance of patients with mild diabetes is often so slight that more than one test is required to confirm or refute the results. The oral glucose tolerance test (OGTT) has for many years been the most commonly used test for detection of mild diabetes. The intravenous glucose (IVGTT) and the intravenous tolbutamide test (IVTT) were inter alia designed to circumvent intestinal absorption, which might influence the result of the oral tolerance test. At present, no objective criteria exist for establishing the superiority of one test procedure over the other in the diagnosis of diabetes mellitus. As pointed out by Lundbaek [2] glucose tolerance tests cannot be used to define diabetes mellitus, but only to define the 'degree of diabeticity'. It would, on the other hand, be desirable if the three most commonly used tests gave the same diagnostic information, i.e. judged the same individuals diabetic or nondiabetic, independently of the tests used.

It is the objective of the present study to compare the diagnostic results obtained with the oral and intra- venous glucose tolerance tests and the intravenous tolbutamide test, in a group of elderly obese and nonobese persons without clinical symptoms of diabetes, whose fasting blood glucose was below $100 \mathrm{mg} / 100$ $\mathrm{ml}$. The aim of the study is, in addition, to elucidate the factors that affect the degree of concordance of the diagnostic results, and finally to establish screening limits for the tests that give the highest degree of agreement.

\section{Methods}

Fifty-six subjects (Table 1) with a fasting blood glucose less than $100 \mathrm{mg} / 100 \mathrm{ml}$ were studied with an OGTT, an IVGTT and with an IVTT. The subjects were all more than 55 years old, and were divided into a non-obese and an obese group. Obesity was defined as a percentage of average body weight $>115$ (Documenta Geigy, Scientific Tables, 6 ed., p. 623, 1960). All subjects consumed a standardized diet containing $300 \mathrm{~g}$ carbohydrate for three days before the tests. The subjects were selected from patients referred to Medical Department M, Aarhus Kommunehospital, because of various musculoskeletal disorders, psychoneurosis, bronchitis and obesity. None of the subjects received drugs known to influence glucose tolerance.

The IVGTT (25 g), OGTT (100 g) and IVTT ( $1 \mathrm{~g})$ were performed as described earlier $[3,4]$.

In order to find the screening limits that give the highest degree of diagnostic agreement between the 
three tests, different criteria were used to classify the tests as diabetic and non-diabetic (Table 2).

The various criteria applied to the $O G T T$ are those of Fajans \& Conn [5], Mosenthal and Barry [6], the UGDP criterion [7] and the criterion used by the author in earlier studies $[3,4]$. These criteria will be referred to in the following as $F \& C, M \& B$, UGDP, and author's.

For the IVGTT three different criteria have been selected, all within the traditional range. Unger and Madison [8] found during IVTT that a $30 \mathrm{~min}$ blood glucose value $77 \%$ of fasting effectively separated diabetics and non-diabetics. In the present analysis we used this level as well as one slightly higher and one slightly lower. of $67 \%$ was, however, associated with a different degree of concordance in diagnosing non-diabetics $(66 \%)$ and diabetics $(83 \%)$. Similar concordance of the tests in diagnosing both diabetics and non-diabetics (obese and non-obese) with our criterion for the OGTT was obtained by a $k$-value of 1.05 for the IVGTT and a blood glucose level $30 \mathrm{~min}$ after tolbutamide of $77 \%$ of the pretest level for the IVTT. The highest agreement using the method of F \& C were 47 and $58 \%$ for respectively the non-obese and the obese group. The corresponding figures for the M \& B method were $60 \%$ for the obese and $54 \%$ for the non-obese group, and for the UGDP criteria 57 and $67 \%$ for the non-obese and obese groups respectively.

Table 1. Clinical data

\begin{tabular}{lllllc}
\hline & $\begin{array}{l}\text { Number } \\
\delta / q\end{array}$ & $\begin{array}{l}\text { Age } \\
\text { years }^{\mathrm{a}}\end{array}$ & $\begin{array}{l}\text { Height } \\
\mathrm{cm}\end{array}$ & $\begin{array}{l}\text { Weight } \\
\mathrm{kg}\end{array}$ & $\begin{array}{l}\text { Percentage of average } \\
\text { body weight }\end{array}$ \\
\hline Non-Obese Subjects & $20 / 11$ & $66 \pm 1.9$ & $166 \pm 2.2$ & $67 \pm 2.5$ & $96 \pm 2.5$ \\
\hline Obese Subjects & $11 / 14$ & $70 \pm 2.0$ & $164 \pm 2.4$ & $85 \pm 2.7$ & $126 \pm 2.8$ \\
\hline \pm S.E.M. & & & &
\end{tabular}

All tests were performed during a hospital stay. The subjects were up and about and not at bedrest except during the night. The tests were performed in the morning after a 12 to $14 \mathrm{hrs}$ fast, with the subjects in the supine position.

Antecubital venous blood was obtained from an indwelling plastic catheter and the blood samples were stored at $-20^{\circ} \mathrm{C}$ until analysis. Blood glucose was determined on whole blood by a glucose oxidase method in single determinations [9], and all blood samples from the same individual were determined in the same assay.

Correlations were carried out with the distributionfree Spearman's test [10] and the 5\% limit was accepted as indicating significance.

\section{Results}

The concordance of the three tests, i.e. the sum of the cases where the diagnostic results of the three tests agreed in percentage of the total number of agreementdisagreement cases, were compared using four different criteria for the OGTT and three for the interpretation of the IVGTT and the IVTT (Table 3). Using the author's criterion, the best agreement (63\%) was found in the non-obese group, when $\mathrm{k}$-values of 1.05 and 1.20 were used as cut-off points in the IVGTT and $30 \mathrm{~min}$ blood glucose values 74 and $77 \%$ of fasting blood glucose values in the IVTT. In the obese the best concordance (67\%) was found using a $\mathrm{k}$-value of 1.20 and $30 \mathrm{~min}$ blood glucose values $74 \%$ of fasting blood glucose values in the IVTT as limits. In the obese group the agreement percentage
The concordance was not increased by using either a higher $(125 \mathrm{mg} / 100 \mathrm{ml})$ or a lower $(115 \mathrm{mg} / 100 \mathrm{ml})$ blood glucose concentration as screening limits for the authors criterion, and a k-value of 1.05 as limits for the IVGTT and a $30 \mathrm{~min}$ blood glucose level $77 \%$ of fasting as cut-off points for the IVTT.

Table 2. Screening limits applied to the tests

OGTT

Fajans \& Conn ${ }^{5}$ Blood glucose $>160 \mathrm{mg} / 100 \mathrm{ml}$ at $1 \mathrm{hr}$ and $>120 \mathrm{mg} / 100 \mathrm{ml}$ at $2 \mathrm{hrs}$

Mosenthal \&

Barry $^{6}$

Blood glucose $>150 \mathrm{mg} / 100 \mathrm{ml}$ at $1 \mathrm{hr}$ and $>100 \mathrm{mg} / 100 \mathrm{ml}$ at $2 \mathrm{hrs}$

$\mathrm{UGDP}^{7}$

Author ${ }^{3.4}$

Sum of blood glucose values at 0,2 and $3 \mathrm{hrs}$ $>500 \mathrm{mg} / 100 \mathrm{ml}$

IVGTT

Lundbaek $^{2} \quad$ k-value a. 0.95

Blood glucose $>120 \mathrm{mg} / 100 \mathrm{ml}$ within $2^{1 / 2} \mathrm{~h}$

b. 1.05

c. 1.20

IVTT

Unger \&

Madison $^{8}$

Blood glucose as percentage of fasting value a. 80

b. 77

c. 74

The reason why the subjects were diagnosed differently using the author's criterion and those of $\mathrm{F} \& \mathrm{C}$ and $\mathrm{M} \& \mathrm{~B}$ was that the subjects jugded nondiabetic or diabetic by our criterion did not fulfill the $1 \mathrm{hr}$ limit of F \& C's criteria and eight out of ten did 
not fulfill $\mathrm{M} \& \mathrm{~B}$ 's criteria for the $1 \mathrm{hr}$ blood glucose concentration.

From Table 4 it can be seen that in those cases where the use of our criterion and the criteria of $F \&$ $\mathrm{C}, \mathrm{M} \& \mathrm{~B}$ and of UGDP gave divergent results, the IVGTT and the IVTT in a high percentage were in results of the non-obese and the obese group differed; while the $30 \mathrm{~min}$ values of the IVTT of the obese group were significantly correlated to all the post glucose values of the OGTT, only the $2^{1 / 2}$ and $3 \mathrm{hr}$ values of the non-obese group were significantly correlated to the $30 \mathrm{~min}$ values of the IVTT. The

Table 3. Corresponding percentages of three different tolerance tests using different criteria for interpretation of the tests

\begin{tabular}{|c|c|c|c|c|c|c|c|}
\hline & \multirow[b]{2}{*}{ k-value } & \multicolumn{3}{|c|}{ Non-obese } & \multicolumn{3}{|c|}{ Obese } \\
\hline & & 0.95 & 1.05 & 1.20 & 0.95 & 1.05 & 1.20 \\
\hline $\begin{array}{l}O G T T \\
\text { Fajans \& Conn's criteria }\end{array}$ & $\begin{array}{l}\text { IVTT }<74 \\
\text { IVTT }<77 \\
\text { IVTT }<80\end{array}$ & $\begin{array}{l}40^{\mathrm{a}} \\
37 \\
27\end{array}$ & $\begin{array}{l}43 \\
36 \\
27\end{array}$ & $\begin{array}{l}47 \\
37 \\
27\end{array}$ & $\begin{array}{l}50 \\
54 \\
58\end{array}$ & $\begin{array}{l}54 \\
54 \\
58\end{array}$ & $\begin{array}{l}54 \\
46 \\
46\end{array}$ \\
\hline Mosenthal \& Barry's criteria & $\begin{array}{l}\text { IVTT }<74 \\
\text { IVTT }<77 \\
\text { IVTT }<80\end{array}$ & $\begin{array}{l}50 \\
47 \\
33\end{array}$ & $\begin{array}{l}57 \\
50 \\
37\end{array}$ & $\begin{array}{l}60 \\
60 \\
37\end{array}$ & $\begin{array}{l}33 \\
42 \\
42\end{array}$ & $\begin{array}{l}42 \\
42 \\
42\end{array}$ & $\begin{array}{l}54 \\
46 \\
42\end{array}$ \\
\hline UGDP criteria & $\begin{array}{l}\text { IVTT }<74 \\
\text { IVTT }<77 \\
\text { IVTT }<80\end{array}$ & $\begin{array}{l}47 \\
50 \\
40\end{array}$ & $\begin{array}{l}53 \\
53 \\
43\end{array}$ & $\begin{array}{l}57 \\
53 \\
40\end{array}$ & $\begin{array}{l}58 \\
63 \\
67\end{array}$ & $\begin{array}{l}63 \\
63 \\
67\end{array}$ & $\begin{array}{l}63 \\
54 \\
54\end{array}$ \\
\hline Author's criterion & $\begin{array}{l}\text { IVTT }<74 \\
\text { IVTT }<77 \\
\text { IVTT }<80\end{array}$ & $\begin{array}{l}57 \\
60 \\
50\end{array}$ & $\begin{array}{l}63 \\
63 \\
53\end{array}$ & $\begin{array}{l}63 \\
60 \\
50\end{array}$ & $\begin{array}{l}54 \\
58 \\
58\end{array}$ & $\begin{array}{l}58 \\
58 \\
58\end{array}$ & $\begin{array}{l}67 \\
58 \\
54\end{array}$ \\
\hline
\end{tabular}

a the number of tests where the diagnostic results of the three tests agreed in percentage of the total number of agreement-disagreemet cases

Table 4. Disagreement between the three kinds of tests using different criteria for interpretation of the OGTT

\begin{tabular}{|c|c|c|c|}
\hline Author's criterion & Fajans \& Conn's criteria & Mosenthal \& Barry's criteria & UGDP's criterion \\
\hline $\begin{array}{l}\text { Of } 20 \text { non-diabetics: } \\
5 / 20 \text { had diabetic IVGTT } \\
\text { and } \\
4 / 20 \text { had diabetic IVTT }\end{array}$ & $\begin{array}{l}\text { Of } 7 \text { diabetics }{ }^{\mathrm{a}} \text { : } \\
6 / 7 \text { had non-diabetic IVGTT } \\
\text { and } \\
7 / 7 \text { had non-diabetic IVTT }\end{array}$ & $\begin{array}{l}\text { Of } 13 \text { diabetics }{ }^{\mathrm{a}}: \\
10 / 13 \text { had non-diabetic IVGTT } \\
\text { and } \\
11 / 13 \text { had non-diabetic IVTT }\end{array}$ & $\begin{array}{l}\text { Of } 2 \text { diabetics }^{\mathrm{a}}: \\
2 / 2 \text { had non-diabetic IVGTT } \\
\text { and } \\
2 / 2 \text { had non-diabetic IVTT }\end{array}$ \\
\hline $\begin{array}{l}\text { Of } 36 \text { diabetics: } \\
8 / 35 \text { had non-diabetic IVGTT } \\
\text { and } \\
13 / 35 \text { had non-diabetic IVTT }\end{array}$ & $\begin{array}{l}\text { Of } 10 \text { non-diabetics: } \\
8 / 10 \text { had diabetic IVGTT } \\
\text { and } \\
5 / 10 \text { had diabetic IVTT }\end{array}$ & 0 non-diabetics & $\begin{array}{l}\text { Of } 7 \text { non-diabetics }{ }^{\mathrm{b}} \text { : } \\
4 / 7 \text { had diabetic IVGTT } \\
\text { and } \\
3 / 7 \text { had diabetic IVTT }\end{array}$ \\
\hline
\end{tabular}

a $O$ the 20 non-diabetics according to the authors criterion.

${ }^{b}$ Of the 36 diabetics according to the authors criterion.

Limit for k-value $=1.05$ and for IVTT $_{30}=77 \%$

accordance with the judgements of the OGTT using our criterion.

Table 5 shows the degree of correlation between the $k$-values of the IVGTT and the blood glucose values of the OGTT at different times. The k-values showed the closest correlation to the blood glucose values during the last $1^{1 / 2} \mathrm{hr}$ of the OGTT. There was no correlation between the $\mathrm{k}$-values and the $1 \mathrm{hr}$ values of the OGTT. The relationship between the OGTT and the IVTT is also seen in Table 5. The $\mathrm{k}$-values of the IVGTT were significantly correlated with the 20-, 30-, 40-, and 50-min values of the IVTT (expressed as percentage of fasting values) in the nonobese group, but only with the 30-, 40-, and 50-min values of the obese group.

\section{Discussion}

The present report compares the three most commonly used tests for diagnosing diabetes mellitus, and adapted the criteria for the classification of the tests 
in order to get the highest degree of concordance between the results of the tests in diagnosing both nondiabetics and diabetics. The study showed that a high frequency of diagnostic agreement can be obtained between the three tests, provided appropriate criteria are used.

The reason why the use of the criteria of $\mathrm{F} \& \mathrm{C}$, $M \& B$ and of UGDP for the OGTT in nearly every instance showed a lower degree of diagnostic agreement with the intravenous tests than the author's criterion (Table 5), may be that the criteria of these three groups include the blood glucose values during the first part of the OGTT. We found that the blood suggest that the first part of the OGTT is mainly determined by intestinal absorption rather than glucose clearing factors.

A high incidence of diagnostic disparity between the OGTT and the IVGTT has been reported by several workers. This discordance may partly be due to the inclusion of blood glucose in the first part of the OGTT in the classification of the tests, and partly due to the screening limits chosen.

Dyck and Moorhouse [17] found a good accord between the OGTT and the IVGTT in diagnosing diabetics: 20 out of 21 subjects with an abnormal OGTT had an abnormal IVGTT (95\%). On the other hand,

Table 5. Correlations between K-values and blood glucose values during OGTT and IVTT

\begin{tabular}{|c|c|c|c|c|c|}
\hline & & \multicolumn{2}{|l|}{ Non-obese } & \multicolumn{2}{|l|}{ Obese } \\
\hline & & $\mathbf{R}$ & $\mathrm{p}$ & $\mathbf{R}$ & $\mathrm{p}$ \\
\hline $\begin{array}{r}\text { K-value versus OGTT } \\
- \\
- \\
- \\
-\end{array}$ & $\begin{array}{l}-30^{\mathrm{a}} \\
-60 \\
-90 \\
-120 \\
-150 \\
-180 \\
\end{array}$ & $\begin{array}{l}-0.023 \\
-0.074 \\
-0.413 \\
-0.500 \\
-0.385 \\
-0.309 \\
\end{array}$ & $\begin{array}{l}\text { N.S. } \\
\text { N.S. } \\
0.05 \\
0.01 \\
0.05 \\
\text { N.S. }\end{array}$ & $\begin{array}{l}-0.384 \\
-0.377 \\
-0.414 \\
-0.484 \\
-0.382 \\
-0.413 \\
\end{array}$ & $\begin{array}{l}\text { N.S. } \\
\text { N.S. } \\
\text { N.S. } \\
0.05 \\
\text { N.S. } \\
0.05\end{array}$ \\
\hline $\begin{array}{r}\text { IVTT-30 versus OGTT } \\
- \\
- \\
- \\
-\end{array}$ & $\begin{array}{l}-30 \\
-60 \\
-90 \\
-120 \\
-150 \\
-180\end{array}$ & $\begin{array}{l}-0.186 \\
-0.203 \\
+\quad 0.147 \\
+\quad 0.273 \\
+0.473 \\
+0.398\end{array}$ & $\begin{array}{l}\text { N.S. } \\
\text { N.S. } \\
\text { N.S. } \\
\text { N.S. } \\
0.02 \\
0.05\end{array}$ & $\begin{array}{l}+0.533 \\
+0.514 \\
+0.664 \\
+0.501 \\
+0.450 \\
+0.443\end{array}$ & $\begin{array}{l}0.01 \\
0.02 \\
0.01 \\
0.02 \\
0.05 \\
0.05\end{array}$ \\
\hline $\begin{array}{c}\text { K-value versus IVTT } \\
- \\
- \\
- \\
-\end{array}$ & $\begin{array}{l}-10^{b} \\
-20 \\
-30 \\
-40 \\
-50 \\
-60\end{array}$ & $\begin{array}{l}-0.255 \\
-0.553 \\
-0.682 \\
-0.777 \\
-0.580 \\
-0.091\end{array}$ & $\begin{array}{l}\text { N.S. } \\
0.01 \\
0.001 \\
0.001 \\
0.01 \\
\text { N.S. }\end{array}$ & $\begin{array}{l}-0.293 \\
-0.396 \\
-0.603 \\
-0.585 \\
-0.524 \\
-0.396\end{array}$ & $\begin{array}{l}\text { N.S. } \\
\text { N.S. } \\
0.01 \\
0.01 \\
0.02 \\
\text { N.S. }\end{array}$ \\
\hline
\end{tabular}

alood glucose concentration $\mathbf{3 0}$ min after the oral glucose load.

b Blood glucose concentration $10 \mathrm{~min}$ after the intravenous tolbutamide injection

glucose values during the first hour of the OGTT were not correlated with either the $k$-values of the obese and the non-obese group, or the $30 \mathrm{~min}$ blood glucose values of the IVTT in the non-obese subjects (Table 5). There was a much better correlation between the $2,2^{1 / 2}$ and $3 \mathrm{hr}$ values than between the ${ }^{1 / 2}, 1$ and $1^{1 / 2}$ $\mathrm{hr}$ values of the OGTT and the $\mathrm{k}$-values and the 30 min values of the IVTT. This indicates that if the three tests are to be mutually compared, the blood glucose values of the first hour of the OGTT should not be included in the criteria for interpretation of the tests.

The fact that the incremental changes in glucose load particularly influence blood glucose relatively late in the glucose tolerance test $[11,12,13,14,15]$, of 40 subjects with normal OGTT, only 25 had a normal IVGTT (63\%). The overall agreement was $74 \%$. If Dyck and Moorhouse had chosen a k-value of 1.30 instead of 1.50 they would have obtained the same overall agreement between the two tests $(74 \%)$. However, the agreement of the two tests in diagnosing diabetics would have been $15 / 21$ (71\%) and in diagnosing non-diabetics $29 / 40$ (73\%). In other words, the balance between the two tests in diagnosing both diabetics and non-diabetics is much better with a $\mathrm{k}$-value of 1.30 than with 1.50 .

Benjamin \& Casper [18] found good agreement between the OGTT and the IVGTT in diagnosing non-diabetics but not in diagnosing diabetics. A higher 
screening limit for either the OGTT or the IVGTT might have given a better concordance. Kahn et al. [19] found that significantly more OGTTs than IVGTTs were abnormal in offspring of two diabetic parents. Either a higher screening limit for the IVGTT or for the OGTT might have given a better concordance between the two tests. Olefsky et al. [16] also found a high degree of disagreement between the OGTT and the IVGTT. When the OGTT was either normal or abnormal, then the chance of having a normal or an abnormal IVGTT was 60\%. If the IVGTT, on the other hand, was abnormal, then the OGTT was abnormal in only $42 \%$ of the cases, and when the IVGTT was normal, the OGTT was normal in 75\%.

O'Sullivan and Mahan [20] tried to evaluate the validity of the criteria of $M \& B, F \& C$, and the United States Public Health Service (USPHS) criteria, in a large group of young patients with subclinical diabetes, by determination of their accuracy in predicting the subsequent development of overt diabetes. The investigators found over a 10 year period that $52 \%$ of patients diagnosed by the USPHS criteria became diabetic, while the more sensitive criteria of $\mathrm{F} \& \mathrm{C}$ and of $\mathrm{M} \& \mathrm{C}$ only showed 32 and $21 \%$ decompensation. This kind of evaluation of the validity of a certain criterion is based on the assumption that the natural history of diabetes is characterized by a progression of diabetes from a mild, asymptomatic state to the overt clinical state of diabetes mellitus. It is, however, well known that many patients with mild diabetes continue to have mild diabetes for the rest of their lives. Criteria based on the assumption that the glucose intolerance progressively deteriorates will exclude the permanently mild diabetic subject.

Reports comparing the IVTT with the two glucose tolerance tests are scarce. Unger \& Madison designed the IVTT and compared the test with the OGTT in a large group of normal and mildly diabetic subjects [8]. They found that the blood glucose concentration at 20 and $30 \mathrm{~min}$, expressed as percent of pretest level, correctly (i.e., were in accordance with the diagnostic results of the OGTT) segregated diabetic patients from non-diabetics in approximately $95 \%$ of cases. Kaplan [21] also found a high degree of concordance between the IVTT and the OGTT. 54 of 55 patients (98\%) with overt diabetes had an abnormal IVGTT. Of 73 subjects with subclinical diabetes and abnormal OGTT, 51 had an abnormal IVTT (70\%). Pote \& Poucher [22], however, found a bad concordance between the IVTT and the OGTT.

This discrepancy previously reported between the diagnostic information obtained by different tests may be explained partly by the screening limits used, and partly by the use of the blood glucose levels in the first part of the OGTT in the screening limits. Our findings show that by using the criteria shown in Table 6 , the overall concordance, i.e., the sum of concordance cases of all three tests, as a percentage of all concordance-discordance cases was about 60\%. At the same time, the mutual concordance between two

Table 6. Screening limits for the tolerance tests

\begin{tabular}{ll}
\hline OGTT $^{\mathrm{a}}$ & Blood glucose fallen or not fallen to $\leq 120 \mathrm{mg} /$ \\
& $100 \mathrm{ml}$ within $21 / 2 \mathrm{~h}$ \\
IVGTT & $\mathrm{k}$-value $>$ or $\leq 1.05$ \\
IVTT & $30 \mathrm{~min}$ blood glucose in per cent of fasting $>$ \\
& or $\leq 77$ \\
\hline
\end{tabular}

a For description of procedure see Methods

tests was about $75 \%$ and was similar in diagnosing diabetics and non-diabetics. This does not mean that the criteria in Table 6 are superior to other screening limits, as they are all arbitrary. It does, however, mean that the concordance-discordance frequency in judging the same individuals diabetic or non-diabetic is higher using the screening limits in Table 6 than with the other criteria. The remaining discordance between two tests in about $1 / 4$ of the subjects may be attributed to intrinsic variability of the test.

\section{References}

1. Keen, H., Jarrett, R. J.: Macroangiopathy - its prevalence in asymptomatic diabetes. In: Early diabetes. pp. 3-9. New York and London: Academic Press 1972

2. Lundbaek, K.: Intravenous glucose tolerance test as a tool in definition and diagnosis of diabetes mellitus. Brit. med. J. 1962 I, $1507-1513$

3. Johansen, K.: Normal initial plasma insulin response in mild diabetes. Metabolism 21, 1177-1180 (1972)

4. Johansen, K.: The spectrum of plasma insulin responses in middle-aged and old non-obese diabetics with various degrees of metabolic derangement. Acta med. scand. 194, 157-164 (1973)

5. Fajans, S. S., Conn, J. W.: The early recognition of diabetes mellitus. Ann. N.Y. Acad. Sci. 82, 208-18 (1959)

6. Mosenthal, H. D., Barry, E.: Criteria for and interpretation of normal glucose tolerance tests. Ann. intern. Med. 33, 1175-1194 (1950)

7. Klimt, C. R., Meinert, C. L., Miller, C. L., Knowles, H. C.: A study of the relationship of therapy to vascular and other complications of diabetes. In: Tolbutamide after ten years, Brook Lodge Symposium, August 1967. New York: Excerpta Medica Foundation Int. Congr. Series No. 149, pp. 261-269, 1967

8. Unger, R. H., Madison, L. L.: A new diagnostic procedure for mild diabetes mellitus: Evaluation of an intravenous tolbutamide response test. Diabetes 7, 455-461 (1958)

9. Christensen, N. J.: Notes on the glucose oxidase method. Scand. J. clin. Lab. Invest. 19, 379-384 (1967)

10. Kendall, M. G.: Rank correlation methods. 2nd ed., pp. 172. London: Griffin 1955 
11. Castro, A., Scott, J. P., Grettie, D. P., Macfarlane, D., Bailey, R. E.: Plasma insulin and glucose responses of healthy subjects to varying glucose loads during threehour oral glucose tolerance tests. Diabetes 19, 842-851 (1970)

12. Chandalia, H. B., Boshell, B. R.: Diagnosis of diabetes: The size and nature of carbohydrate load. Diabetes 19, $863-869$ (1970)

13. Sisk, C. W., Burnham, C. E., Stewart, J., McDonald, G. W.: Comparison of the 50 and 100 gram oral glucose tolerance test. Diabetes 19, 852-862 (1970)

14. Förster, H., Halsbeck, M., Mehnert, H.: Metabolic studies following the oral ingestion of different doses of glucose. Diabetes 21, 1102-1108 (1972)

15. Christensen, N. J., Ørskov, H., Hansen, Aa. P.: Significance of glucose load in oral glucose tolerance tests. Acta med. scand. 192, 337-342 (1972)

16. Olefsky, J. M., Farquhar, J. W., Reaven, G. M.: Do the oral and intravenous glucose tolerance tests provide similar diagnostic information in patients with chemical diabetes mellitus? Diabetes 22, 202-209 (1973)

17. Dyck, D. R., Moorhouse, J. A.: A high dose intravenous glucose tolerance test. J. clin. Endocr. 20, 1032-1038 (1966)
18. Benjamin, F., Casper, D. J.: Comparative validity of oral and intravenous glucose tolerance tests in pregnancy. Am. J. Obstet. Gynec. 97, 488-492 (1967)

19. Kahn, C. B., Soeldner, J. S., Gleason, R. E., Rojas, L., Camerini-Davalos, R. A.: Clinical and chemical diabetes in offspring of diabetic couples. New Engl. J. Med. 281, $343-347$ (1969)

20. O'Sullivan, J. B., Mahan, C. M.: Prospective study of 352 young patients with chemical diabetes. New Engl. J. Med. 278, 1038-1041 (1968)

21. Kaplan, N. M.: Tolbutamide tolerance test in carbohydrate metabolism evaluation. Arch intern. Med. 107, $212-224$ (1961)

22. Pote, Jr., W. W. H., Poucher, R. L.: Comparative results of three tests for diabetes in normal persons. Diabetes 11 (suppl.), 132-135 (1962)

K. Johansen, M. D.

Medical Dept. F

Glostrup Hospital

DK-2600 Glostrup

Denmark 